\title{
Evaluation of the robustness of maximum sustainable yield based management strategies to variations in carrying capacity or migration pattern of Atlantic bluefin tuna (Thunnus thynnus) ${ }^{1}$
}

\author{
Laurence T. Kell and Jean-Marc Fromentin
}

\begin{abstract}
In this study, we examine the performances of current stock assessment methods with respect to their ability to (i) provide estimates of maximum sustainable yield (MSY), $F_{\mathrm{MSY}}$, and $B_{\mathrm{MSY}}$ and (ii) assess stock status and exploitation level relative to MSY targets. The robustness of the current International Commission for the Conservation of Atlantic Tunas (ICCAT) management strategy is then evaluated with respect to uncertainty about the true population dynamics and contrasted with a simpler management strategy based solely on a size limit. Reference points are more robust to dynamic uncertainty than the estimates of absolute values and trends in $F$ and spawning stock biomass. However, their performances depend on the underlying dynamics (they perform better when fluctuations come from changes in the carrying capacity than migration) and on when they are implemented relative to the intrinsic cycle of the population. Reference points based on $F$ were less biased and more precise than those based on biomass and (or) yield. Although $F_{0.1}$ appeared to be the best proxy for $F_{\mathrm{MSY}}$, it cannot indicate past and current levels of exploitation relative to $F_{\mathrm{MSY}}$ when there is uncertainty about the dynamics. Finally, the $F_{0.1}$ management strategy of ICCAT performed only slightly better than a simpler strategy based on size limit and led to lower catch levels.

Résumé : Dans cette étude, nous testons les performances des méthodes d'évaluation des stocks courantes au regard : (i) de leur capacité à fournir de bonnes estimations de la production maximale equilibrée (PME), $F_{\mathrm{PME}}$ et $B_{\mathrm{PME}}$ et (ii) d'évaluer l'état du stock et le niveau d'exploitation par rapport à ces points de référence basés sur la PME. Nous évaluons ensuite la robustesse de la stratégie actuelle de gestion de la CICTA (Commission Internationale pour la Conservation des Thonidés de l'Atlantique (basée sur la PME) aux incertitudes sur la dynamique de population et la comparons à une procédure de gestion plus simple basée sur une taille minimale. Les points de référence sont plus robustes aux incertitudes de dynamique que les estimations des valeurs absolues et les tendances de $F$ et de la biomasse reproductrice. Cependant, leurs performances dépendent de la dynamique sous-jacente (les résultats étant meilleurs quand les fluctuations proviennent de changements dans la capacité de charge que lorsqu'ils résultent de changements migratoires) et de la période à laquelle ils sont implémentés par rapport au cycle intrinsèque de la population. Les points de référence basés sur les $F$ sont plus précis et moins biaisés que ceux calculés à partir des biomasses ou captures. Bien que $F_{0,1}$ apparraisse la meilleure approximation de $F_{\mathrm{PME}}$, il reflète cependant mal les niveaux présents et passés de l'exploitation par rapport à $F_{\mathrm{PME}}$ quand il existe des incertitudes dans la dynamique. Finalement, la stratégie de gestion de la CICTA $\left(F_{0,1}\right)$ ne donne des résultats que légèrement meilleurs qu'une plus simple stratégie basée sur une taille limite et conduit systématiquement à des niveaux de captures bien plus bas.
\end{abstract}

\section{Introduction}

Management of tunas must be consistent with the Agreement for the Implementation of the Provisions of the United Nations Convention of the Law of the Sea of 10 December 1982 relating to the Conservation and Management of Straddling Fish Stocks and Highly Migratory Fish Stocks (Doulman 1995) and with the precautionary approach (Food and Agricultural Organization of the United Nations (FAO) 1996). Although actual management of Atlantic bluefin tuna (Thunnus thynnus) is the responsibility of the International Commission for the Conservation of Atlantic Tunas (ICCAT), whose Convention states that "The Commission may, on the basis of scientific evidence, make recommendations designed to maintain the populations of tuna and tunalike fishes that may be taken in the Convention area at levels

Received 4 April 2006. Accepted 17 December 2006. Published on the NRC Research Press Web site at cjfas.nrc.ca on 21 June 2007. $\mathrm{J} 19257$

L.T. Kell. ${ }^{2}$ Cefas, Lowestoft Laboratory, Pakefield Road, Lowestoft, Suffolk, NR33 0HT, UK.

J.-M. Fromentin. IFREMER, Centre de Recherche Halieutique Méditerranéen et Tropical, BP 171, 34203 Sète CEDEX, France.

${ }^{1 \odot}$ British Crown copyright, 2006.

${ }^{2}$ Corresponding author (e-mail: laurence.kell@cefas.co.uk). 
Table 1. List of the various options used to set up the scenarios for the operating model and sampling process.

\begin{tabular}{ll}
\hline Operating model and sampling procedures options \\
\hline Hypotheses & Recruitment $\left(H_{R}\right)$ \\
& Migration $\left(H_{M}\right)$ \\
Amplitude & Equal to that in observed catches \\
Steepness & 0.75 \\
& 0.90 \\
Historical $F$ s & Constant $F$ being equal to $50 \%$ of $F_{\text {MSY }}$ \\
& Constant $F$ being equal to $F_{\text {MSY }}$ \\
& Constant $F$ being equal to $150 \%$ of $F_{\text {MSY }}$ \\
& Linear increase in effort corresponding to an increase in fishing mortality from $50 \%$ of $F_{\text {MSY }}$ to 250\% \\
& of $F_{\text {MSY }}$ over a full population cycle, i.e., 110 years. \\
Phases at starting point & Peak \\
& Middle of the decreasing slope \\
& Bottom \\
Middle of the increasing slope \\
Observation error model & Method of Arrizabalaga (2005) \\
Misreporting & Based on alternative catch used in ICCAT stock assessment (see ICCAT 2003b) \\
Length of runs & A full long-term cycle, i.e., 110 years \\
\hline
\end{tabular}

which will permit the maximum sustainable catch" (ICCAT 2003a). Maximum sustainable catch is generally assumed to be synonymous with maximum sustainable yield (MSY). However, the MSY concept has been criticised by fish biologists for many years, because in many cases, it is not a robust objective in the face of uncertainty (e.g., owing to the natural stochastic variation in biological processes), which can mask the effects of exploitation, so that initial overexploitation is not detectable until it is severe and often irreversible. Rosenberg and Restrepo (1994) showed that stocks managed to provide MSY may not lead to sustainable and (or) optimal management because of uncertainties associated with interpretation of data and the simplifying assumptions made when modelling biological processes. Furthermore, exploitation, even at moderate levels, may induce complex and important modifications in population resistance and resilience through, e.g., changes in habitat, population structure, genetic diversity, or trophic interactions (e.g., Jennings et al. 2002; Birkeland and Dayton 2005). Failure to take such uncertainty into account when using biological reference points may lead to stock collapse, and several fishing-mortality-based reference points have led to unsustainable exploitation (Punt 2000; Dorn 2002).

When long-term fluctuations in catch occur independently from exploitation, Fromentin and Kell (2007) showed that the perception of the stock strongly depends on the underlying mechanism. Where fluctuations were caused by changes in carrying capacity, the stock assessment procedure was able to estimate stock size and fishing mortality rates accurately, but failed if the fluctuations resulted from changes in migration patterns (or availability to fishing). Although the true underlying mechanism is currently unknown, there is knowledge about the biology of bluefin tuna (e.g., they have seasonal spawning and limited spawning grounds) that may make it possible to develop biological monitoring programmes to resolve uncertainty about stock productivity and status (Fromentin and Kell 2007). However, first, it must be determined if current procedures are robust to uncertainty about the dynamics; therefore, in this study we evaluated the performances of stock assessment methods with respect to (i) their ability to provide estimates of MSY, $F_{\mathrm{MSY}}$, and $B_{\mathrm{MSY}}$ and (ii) assessing stock status and exploitation level relative to these MSY targets. We then tested the robustness of the current ICCAT management strategy (i.e., based on MSY) to uncertainty about the true dynamics and historical exploitation levels and contrasted it with a simpler management strategy, with fewer data and less analytical requirements, based on size limits. Finally, we aim to answer the following questions: Can we estimate population status? Can we estimate MSY-based reference points and (or) stock status, relative to these? What are appropriate strategies for achieving management objectives?

\section{Material and methods}

The simulation framework used within this study models both the "real" and the "perceived" systems. It therefore implicitly acknowledges the presence of a variety of sources of uncertainty, as categorized by Rosenberg and Restrepo (1994). The "real" stock and fishery dynamics are represented as the operating model, from which simulated data are sampled. These data are used within a management procedure (MP) to $(i)$ assess the status of the stock and (ii) apply management controls to the fishery and feed back into the "real" system.

\section{The operating model}

Assumptions and parameters used to model the population and fleet dynamics in the operating model (OM) were the same as in Fromentin and Kell (2007) and are summarised in Table 1. Again two alternative hypotheses about the OM dynamics were evaluated: the long-term fluctuations observed in trap catches result either from changes in the carrying capacity (or virgin biomass, $H_{K}$ ) or from changes in migratory patterns that affect the proportion of mature bluefin tuna entering the Mediterranean Sea each year to reproduce $\left(H_{M}\right)$. However, here we also considered stochastic variations in recruitment (although no stochasticity was 
included in parameters such as natural mortality, weight-at-age, or selection pattern for clarity and to increase the power to compare performance across scenarios). A Beverton and Holt (1957) stock-recruitment relationship was assumed, with lognormal errors and a coefficient of variation (CV) of $30 \%$, consistent with ICCAT estimates of recruitment variability.

\section{The management procedure}

The MP is the specific combination of ( $i$ ) the sampling regime, (ii) the stock assessment method, (iii) the biological reference points, and (iv) the management strategies. Here the MP is based on the ICCAT management regime applied to Atlantic bluefin tuna (ICCAT 2003b).

Representing management objectives quantitatively is often one of the most difficult tasks to accomplish when evaluating management strategies as objectives are seldom defined in an operational sense. For example, in the case of ICCAT, the objective is maximum sustainable catch, which although often interpreted as MSY, can be obtained in a variety of ways. In the same way, managers often experience great difficulty in determining how objectives can be expressed quantitatively when managing fleets by effort control or technical measures (Kirkwood and Smith 1996; Sainsbury et al. 2000). There is also often a wide range of possible management objectives largely of a qualitative nature.

\section{Sampling regime}

The sampling regime corresponds to the collection of commercial catch data and the derivation of catch numbersat-age and catch per unit effort (CPUE). These data were generated by the observation error model in which growth, maturity, and natural mortality-at-age were sampled without error from the OM (values were the same as those used in the 2002 stock assessment and did not vary between years; see Fromentin and Kell (2007) for more details). However, catch-at-age was sampled with random error (from a multinomial distribution) based on the study of Arrizabalaga et al. (2005), who used Monte Carlo simulation of monthly catch-at-size data of some fleets to estimate measurement errors in the whole catch-at-age. These data could then be used to estimate the correlations between ages and the mean-variance relationship for each age to derive the covariance matrix for sampled catch-at-age. However, we fixed the $\mathrm{CV}$ for all ages at $20 \%$ to avoid high variances at some ages (mostly caused by a lack of monitoring).

\section{Assessment method and biological reference points}

The stock assessment model used is virtual population analysis (VPA) calibrated using CPUE data, as used to perform bluefin tuna stock assessments by ICCAT (here referred as ADAPT-VPA; Porch 1997; ICCAT 2003b). ADAPT-VPA uses total catch-at-age data, conditional on numbers (or fishing mortality) at age of the oldest age in each cohort where the latter is estimated using CPUE from the fishery, to recreate historical numbers and fishing mortality-at-age. It is also assumed that catch and natural mortality are known without error, that there is no immigration or emigration, and that the stock is homogeneous. The VPA was run over 30 years, as this is currently done within ICCAT stock assessments (ICCAT 2003b, 2007).
Biological reference points (BRP) chosen for management were all proxies for $F_{\mathrm{MSY}}$, i.e., $F_{0.1}, F_{\mathrm{max}}, F_{30 \% \mathrm{SPR}}$ and $F_{40 \% \mathrm{SPR}}$, or the corresponding values of MSY and $B_{\mathrm{MSY}}$ (calculated from the yield- and spawner-per-recruit curves $\times$ the mean recruitment), where $F_{0.1}$ is the value of fishing mortality for which the slope of the yield-per-recruit curve (as a function of $F$ ) is $1 / 10$ th of the value at the origin, $F_{\max }$ is the value of fishing mortality that maximises the yield-per-recruit, and $F_{30 \% \text { SPR }}$ and $F_{40 \% \text { SPR }}$ are the fishing mortalities corresponding to values of fishing mortality where spawner-per-recruit is $30 \%$ and $40 \%$, respectively, of virgin spawner-per-recruit (i.e., at zero fishing mortality).

\section{Management strategies}

Two contrasting management regimes were considered: (i) a harvest control rule (HCR) based on $F_{0.1}$ (mimicking the ICCAT harvest control rule), where the total allowable catch (TAC) is set equivalent to a level of fishing mortality equal to $F_{0.1}$, based on VPA and a short-term forecast; (ii) an alternative simple regime based on a change in selection pattern of immature fish (i.e., younger than 5 years) equivalent to a reduction in $F$ of $75 \%$ of these ages.

For each experimental scenario, management strategies were run for 15 years into the future (i.e., years 111 to 125 ), and population parameters and biological reference points were re-estimated using ADAPT-VPA. A 15-year period was chosen because it corresponds to the generation time of Atlantic bluefin tuna (Fromentin and Kell 2007).

ICCAT has previously expressed concern about the quality of the catch and effort data (ICCAT 2003b, 2005), and various possible causes for misreporting of catches (including nonreporting by members and nonmember countries) have been postulated. One of the main reasons for misreporting appears to be related to the implementation of quotas for East Atlantic and Mediterranean bluefin tuna in 1996 and 1998 (Fromentin and Powers 2005). It was subsequently believed that this resulted in over-reporting before the period 1996-1998 and under-reporting since. Although little quantitative information is available to characterize misreporting precisely, ICCAT proposed an alternative catch scenario, based on 15\% over-reporting for the period 1993-1997 and $15 \%$ under-reporting from 1998 onwards, in order to conduct sensitivity trials during the last stock assessment (ICCAT 2003b). We therefore added an implementation error model to reflect the fact that current harvest control rules may be poorly endorsed using the same scenario as that applied in the 2002 stock assessment.

All experimental scenarios (including the four historical fishing mortalities, the four starting points, and the two steepness values and the possibility (or not) of misreporting) generate 64 simulations for each hypothesis $\left(H_{K}\right.$ and $H_{M}$; see Table 1). For each scenario, 1000 Monte Carlo simulations were run, with random variables as stated above. Stochastic runs including recruitment and observation error were performed for 1000 simulations.

\section{Results}

All the scenarios (with their Monte Carlo simulations) are summarised and compared by inspection of box-and-whisker plots (Figs. 1 to 5), where the performance of the MP is evaluated by dividing the examined indicator estimated from the 
Fig. 1. Performance in assessing stock status relative to $F$ and spawning stock biomass (SSB) by hypothesis (carrying capacity and migration) and phase under misreporting and increasing $F$ scenarios (simulations include stochastic recruitment in the operating model and random errors in the catch-at-age in the sampling procedure). Scenarios are compared by inspection of box-and-whisker plots where the performance of the management procedure (MP) is evaluated by dividing the examined indicator estimated from the MP by the corresponding true value of the operating model (OM) so that unbiased and precise MP estimates will lead to values close to 1.0 with low variance. Boxes show the interquartile range and median, whiskers represent 1.5 times the interquartile range. $(a)$ All scenarios with constant historical $F$ s under the carrying-capacity hypothesis $\left(H_{K}\right) ;(b)$ all scenarios with constant historical $F$ s under the migration hypothesis $\left(H_{M}\right) ;(c)$ same as $(a)$ with misreporting; $(d)$ same as $(b)$ with misreporting; $(e)$ all scenarios with increasing historical $F$ s under the $H_{K}$; $(f)$ all scenarios with increasing historical $F$ s under the $H_{M}$.

Carrying-capacity hypothesis
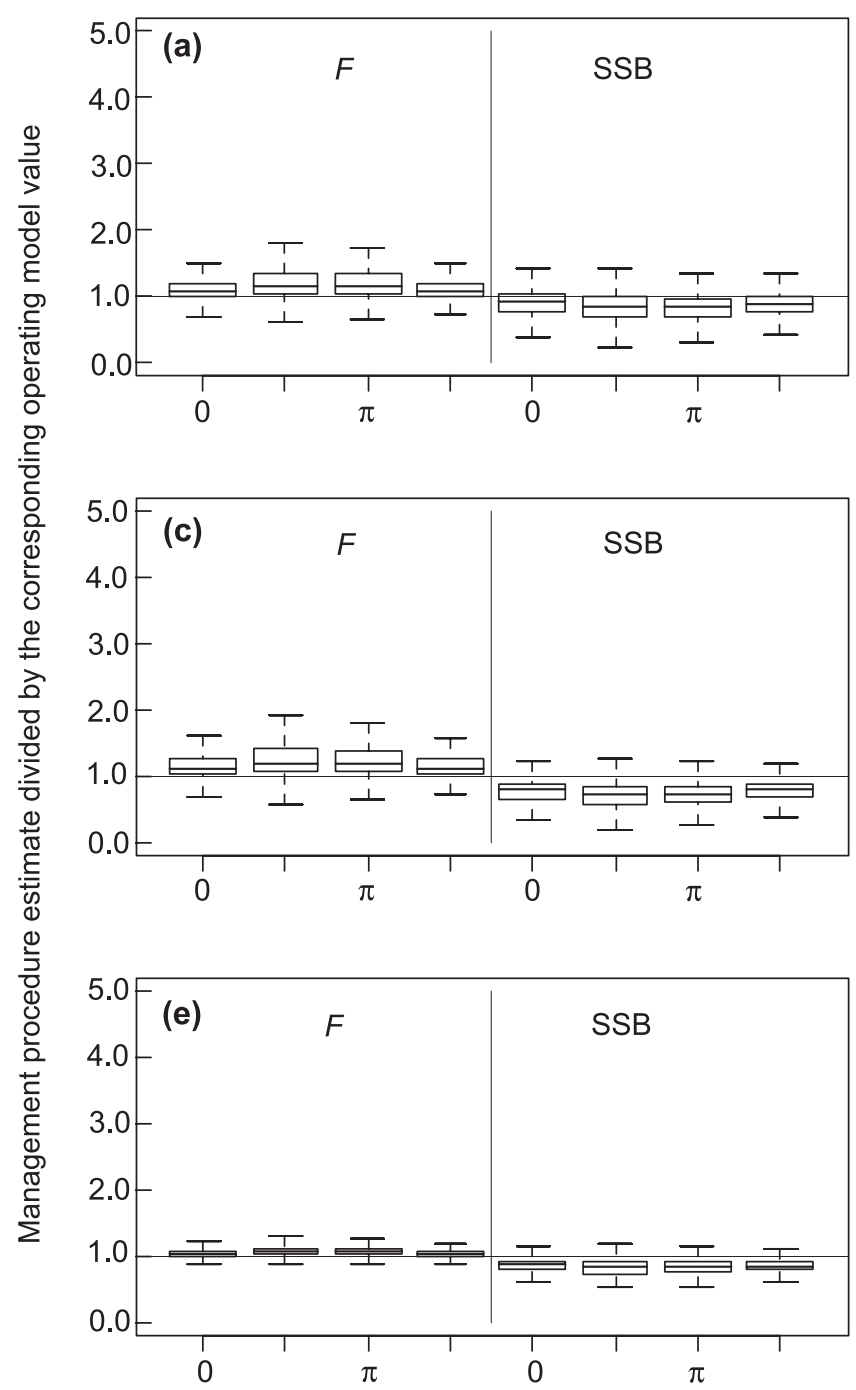

MP by the corresponding true value of the OM so that unbiased and precise MP estimates will lead to values close to 1.0 with low variance. Boxes show the interquartile range and medians, whiskers indicate 1.5 times the interquartile range.

\section{Ability to detect population status}

The ability of the MP to estimate $F$ and SSB is evaluated in Fig. 1, but in comparison with Fromentin and Kell (2007), these simulations also include stochastic recruitment in the operating model and random errors in the catch-at-age in the sampling procedure (see above). As expected from Fromentin and Kell (2006), the main difference results from the un-
Migration hypothesis
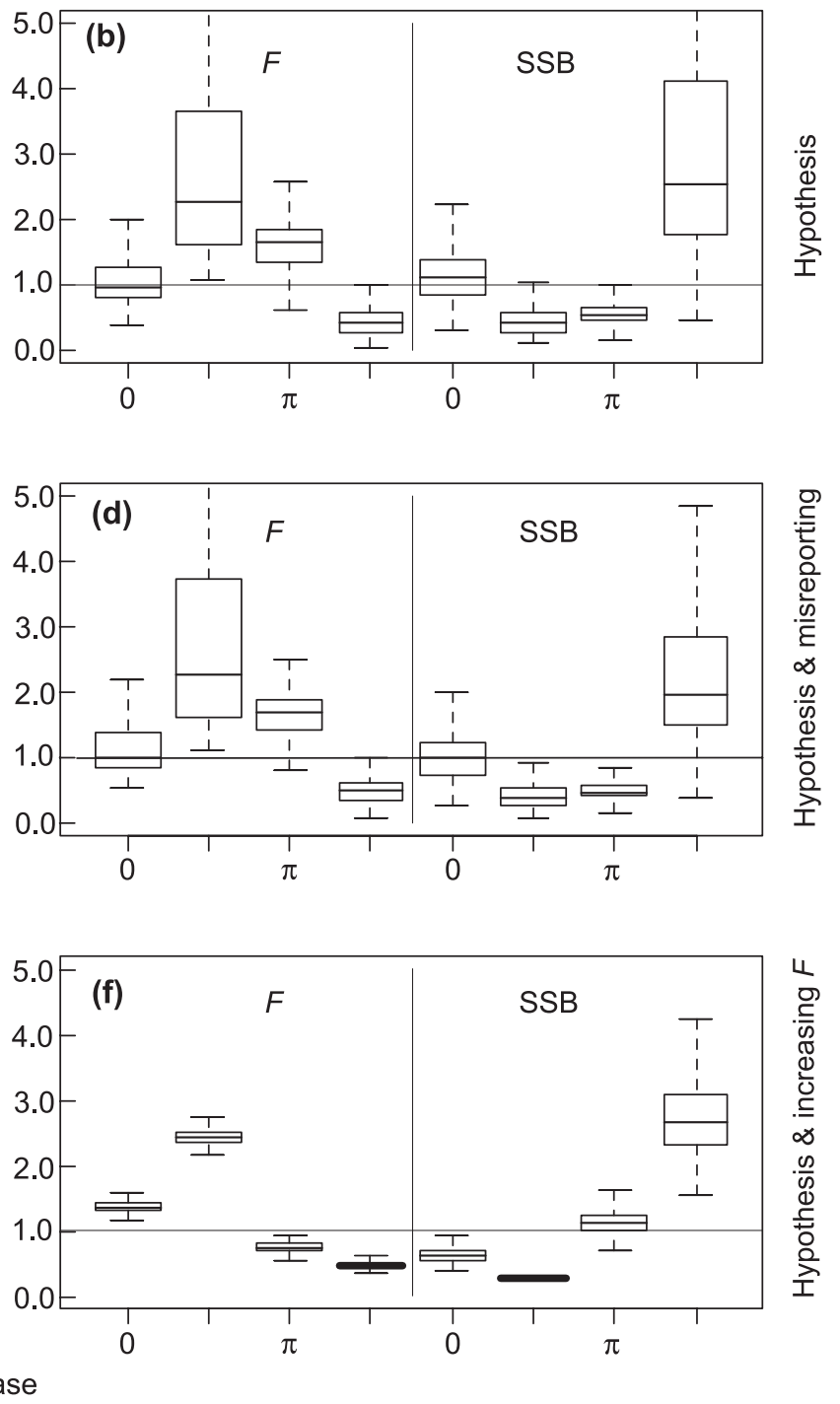

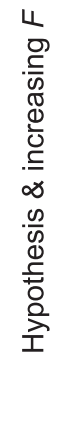

derlying hypothesis (i.e., carrying capacity, $H_{K}$, or migration, $H_{M}$ ). Whatever the scenario (i.e., constant $F$, misreporting, or increasing $F$ ), the box plots under $H_{M}$ display both strong bias and large variability, reflecting the poor performance of VPA under this hypothesis. Phases in the cycle of the biological process hypothesised (or initial conditions of the VPA) are also clearly important, because for some phases $(\pi / 2$ and $3 \pi / 2)$, the bias in SSB can be greater than $300 \%$, whereas for another starting point (0), the performance of the VPA appears to be better (Figs. $1 b$, $1 d, 1 f)$. In contrast, the MP under $H_{K}$ exhibits low bias and more precise $F$ and SSB trends in all cases. The effect of 
Fig. 2. A comparison of maximum sustainable yield (MSY) based biological reference points (BRP) estimated by the management procedure and divided by the corresponding true (i.e., operating model, OM) values of $F_{\mathrm{MSY}}$, MSY, and $B_{\mathrm{MSY}}$. $(a)$ BRP based on $F$ under the carrying-capacity hypothesis $\left(H_{K}\right) ;(b)$ BRP based on $F$ under the migration hypothesis $\left(H_{M}\right)$; $(c)$ BRP based on yield under $H_{K}$; (d) BRP based on yield under $H_{M}$; (e) BRP based on spawning stock biomass (SSB) under $H_{K}$; $(f)$ BRP based on SSB under $H_{M}$.

Carrying capacity hypothesis
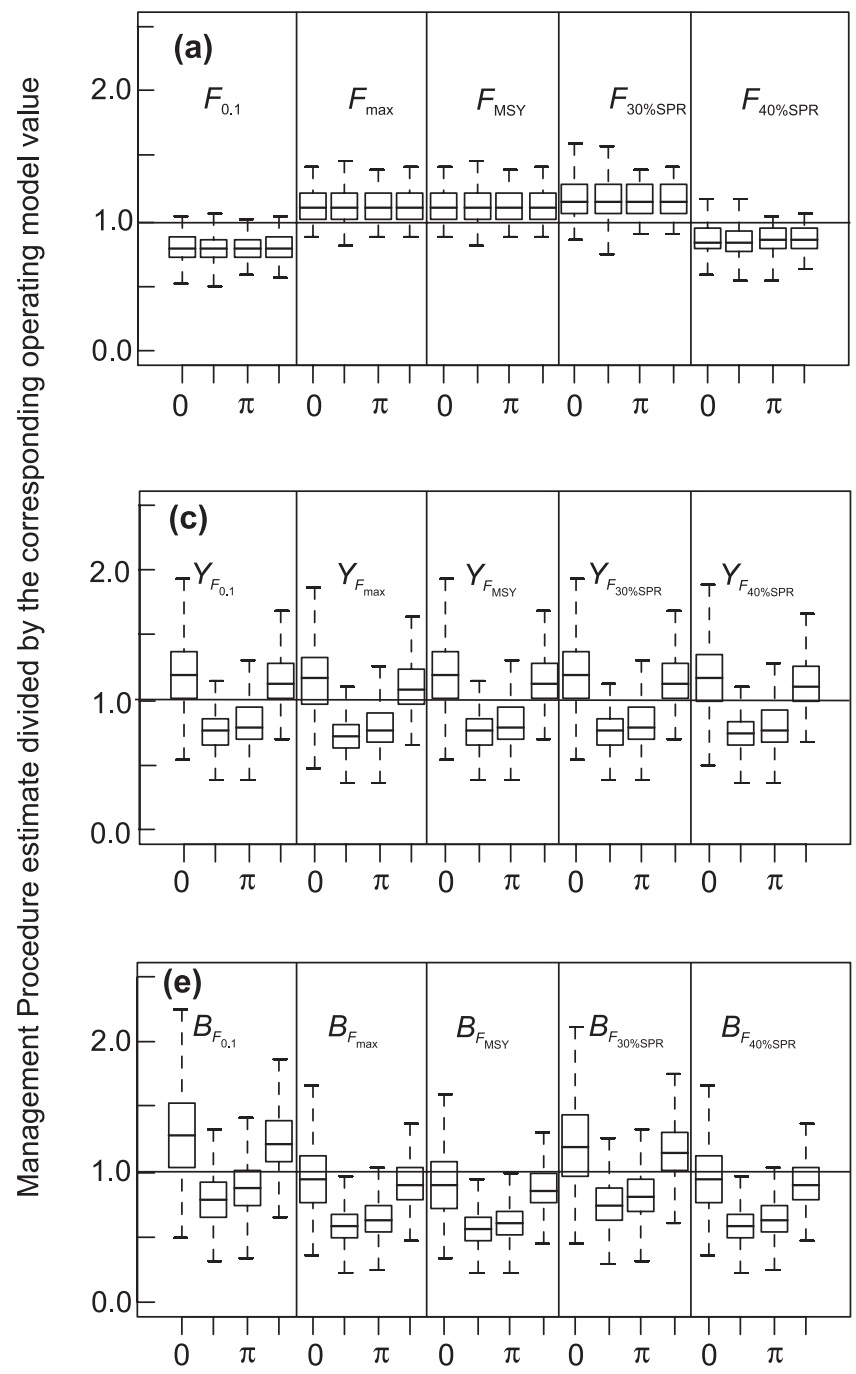

Migration hypothesis
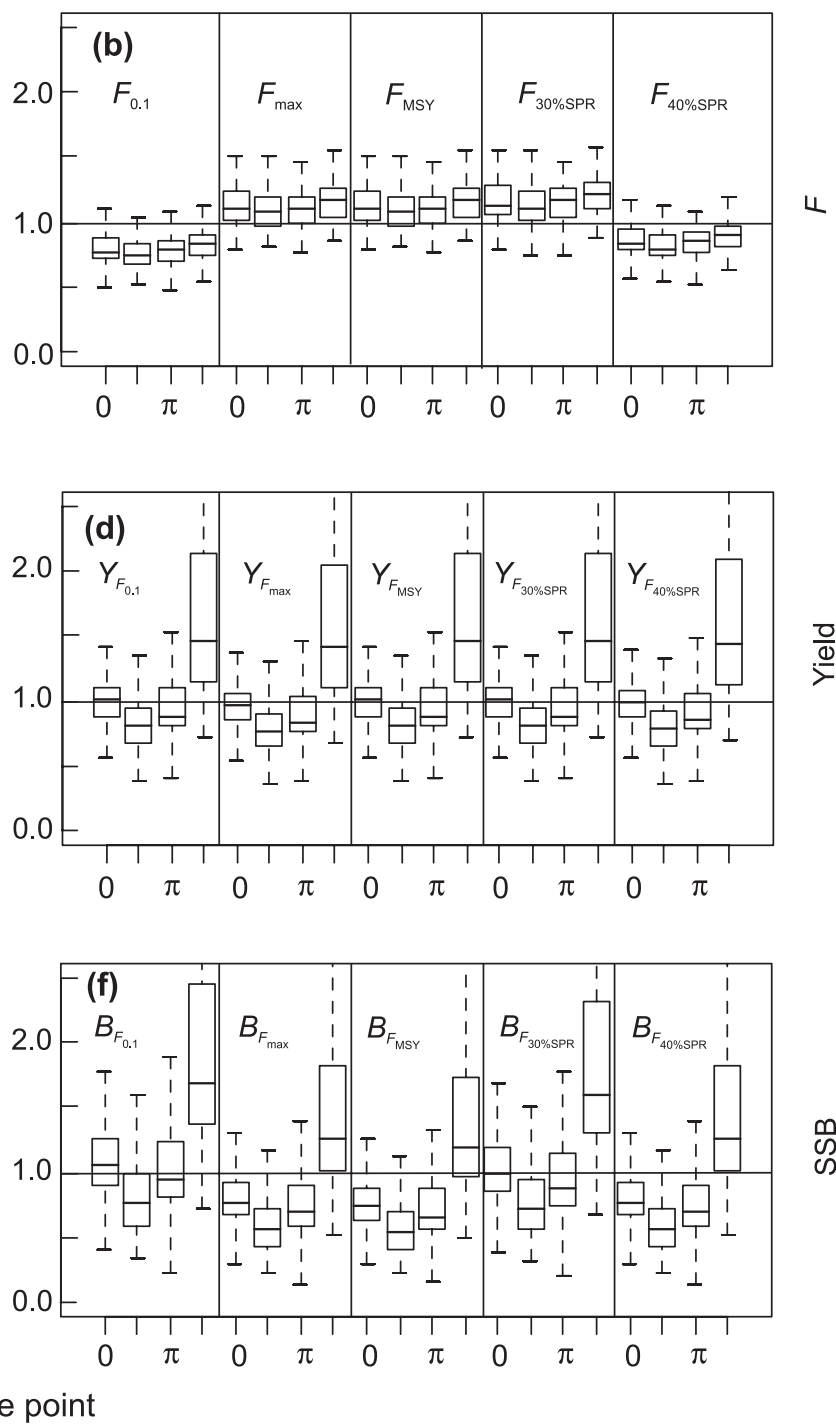

misreporting appears to be relatively minor compared with the hypothesis about the dynamics and the effect of the starting point (although the variability strongly increases under $H_{M}$; Figs. $1 c, 1 d$ ). Increasing historical $F_{\mathrm{s}}$ (Figs. 1e, $1 f$; as steepness (results not shown)) have little effect. These results thus confirm that the MP consistently fails to estimate accurately trends in $F$ and SSB under $H_{M}$ (and can further give an optimistic perception of the stock in some cases), but it performs well in most cases under $H_{K}$, even when misreporting is assumed.

\section{Performance of reference points}

The performance of the MP in providing proxies of MSY, $F_{\text {MSY }}$ and $B_{\text {MSY }}$ is evaluated (Fig. 2). For each hypothesis and each phase, a range of proxies for $F_{M S Y}$ was calculated within the MP (i.e., $F_{0.1}, F_{\max }, F_{30 \% \mathrm{SPR}}, F_{40 \% \mathrm{SPR}}$ ), along with the corresponding proxies for $B_{\mathrm{MSY}}$ and MSY (derived from yield- and spawner-per-recruit assuming that recruitment was equal to the mean of the last 5 years). Here again, ratios close to 1 indicate good performance of the MP. In contrast to Fig. 1, the differences between hypotheses $\left(H_{M}\right.$ and $H_{K}$ ) are not so critical, especially for BRPs based on $F$ (Figs. $2 a, 2 b$ ). In other words, the performances of the BRPs appear to be more robust to uncertainty in the dynamics than are the stock assessment estimates (Figs. 1, 2). This is because BRP are based on equilibrium calculations and selectivity patterns, which are biased by factors other than the underlying dynamics. The biggest difference between scenarios is for initial conditions (i.e., phases between exploitation and natural long-term cycle), i.e., is availability or carrying capacity currently increasing (decreasing) or at a peak (nadir). However, the variability remains much higher under $H_{M}$ than under $H_{K}$, especially for yield- and SSBbased BRP (Figs. 2d, 2f). In general, $F_{0.1}$ (and secondarily 
Fig. 3. A comparison of $F_{0.1}$-based reference points (estimated by the management procedure) divided by the corresponding true (i.e., operating model, OM) $F_{\mathrm{MSY}}(a)$ All scenarios with constant historical $F$ s under the carrying-capacity hypothesis $\left(H_{K}\right)$; $(b)$ all scenarios with constant historical $F$ s under the migration hypothesis $\left(H_{M}\right) ;(c)$ same as $(a)$ with misreporting; $(d)$ same as $(b)$ with misreporting; (e) all scenarios with increasing historical $F$ s under the $H_{K}$; $(f)$ all scenarios with increasing historical $F$ s under the $H_{M}$.

Carrying-capacity hypothesis
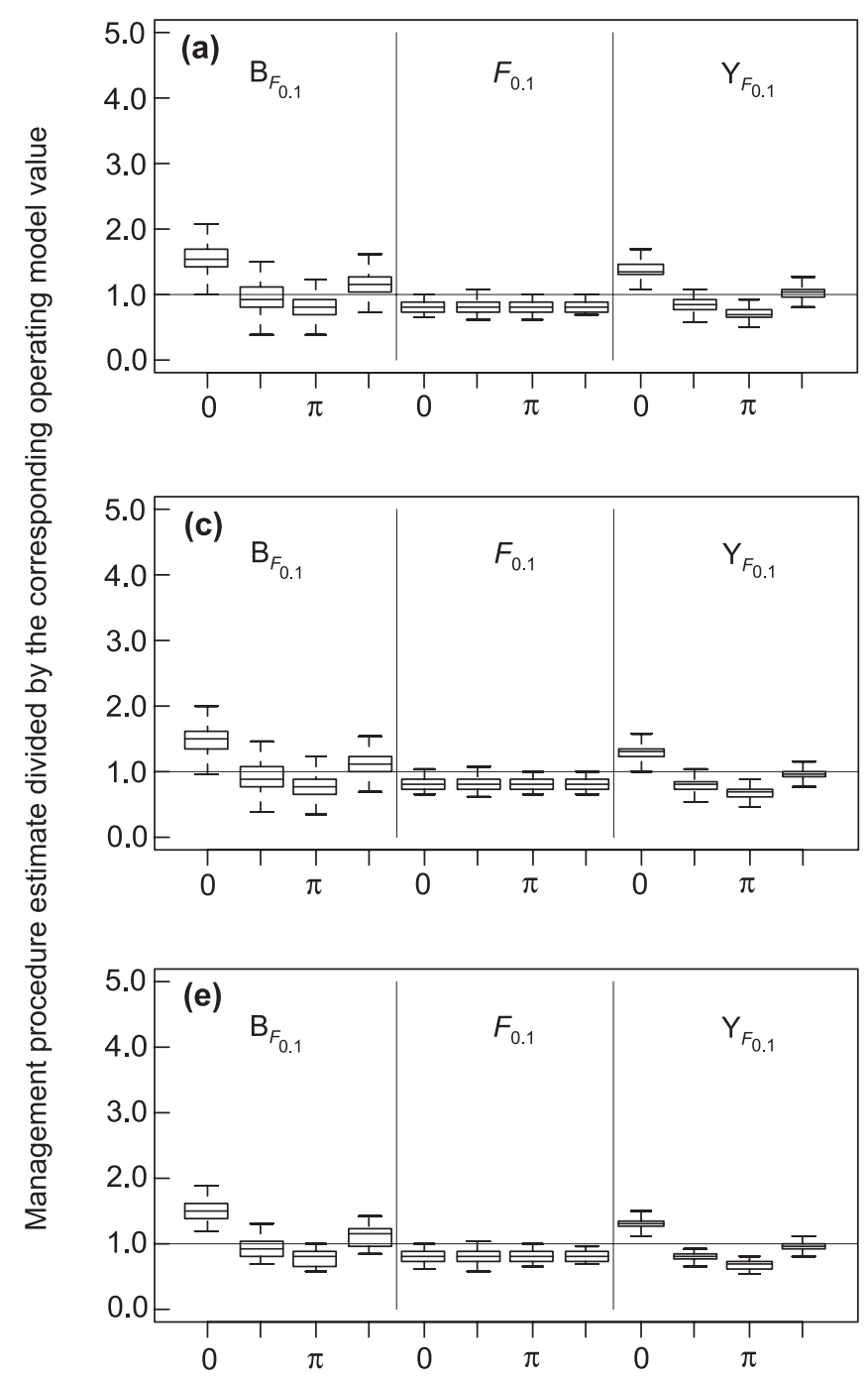

$\mathrm{F}_{40 \% \mathrm{SPR}}$ ) gives better and more consistent results than the other BRPs $\left(F_{0.1}\right.$ values are indeed always around 1 and display little variance among scenarios; Fig. 2). $F_{0.1}$ therefore appeared to be the best proxy for $F_{\mathrm{MSY}}$, so subsequent analyses are only presented for $F_{0.1}$.

The $F_{0.1}$-based reference points from the MP (i.e., $B_{F_{0.1}}$, $\left.F_{0.1}, Y_{F_{0.1}}\right)$ divided by the corresponding MSY-based quantity from the OM (i.e., $B_{\mathrm{MSY}}, F_{\mathrm{MSY}}, \mathrm{MSY}$ ) are presented (Fig. 3). The performances of $F_{0.1}$-based reference points in providing a good proxy for $F_{\mathrm{MSY}}$ is generally better under $H_{K}$ than under $H_{M}$, especially for increasing $F$ scenarios (Figs. $3 e$, $3 f)$. For some phases, biomass- and yield-based reference points $\left(B_{F_{01}}\right.$ and $\left.Y_{F_{01}}\right)$ are strongly biased (up to 200\%) and can further display large variability (especially for increasing $F$ under $H_{K}$; Fig. $3 f$ ). By contrast, $F_{0.1}$ reference points are more consistent among starting points and hypotheses. They
Migration hypothesis
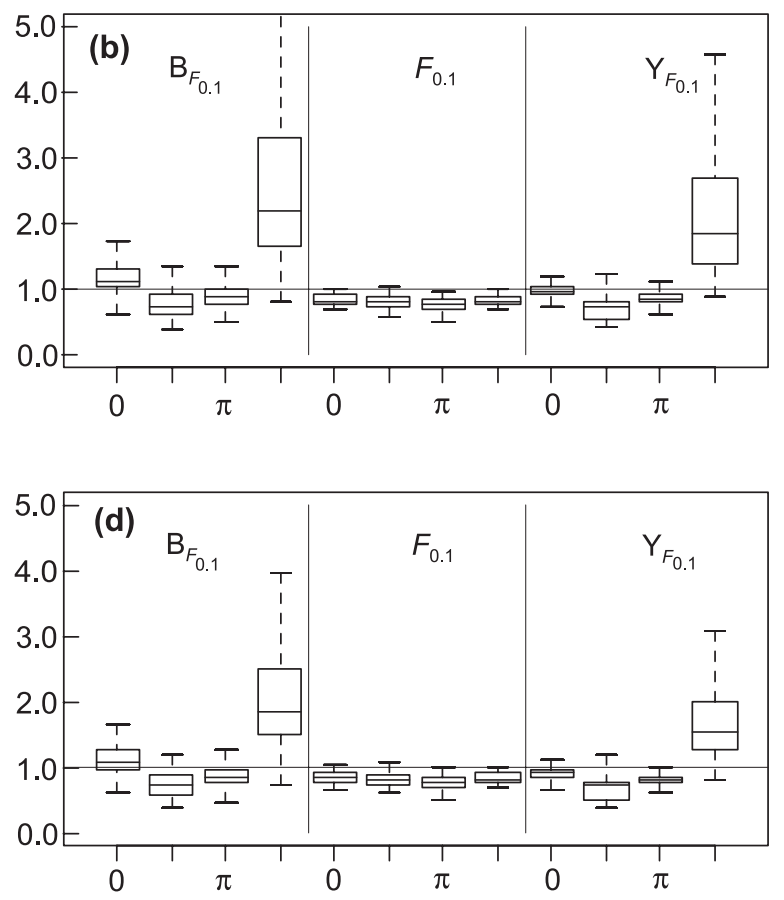

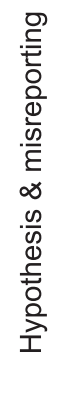

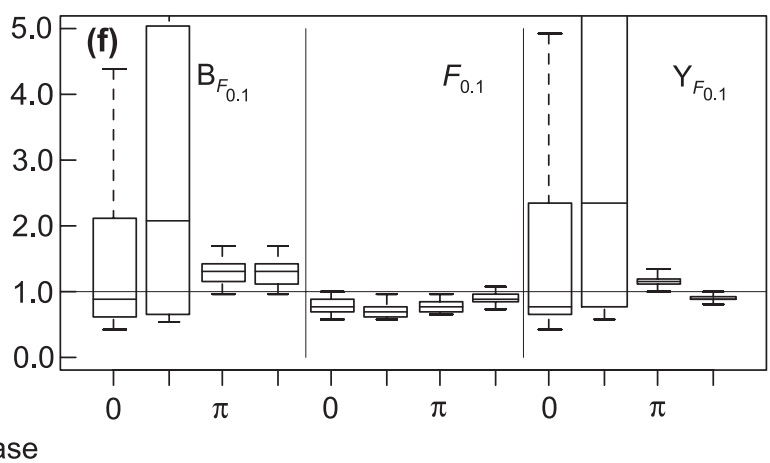

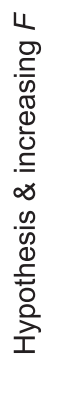

are always precise (i.e., they display little variability) and are only slightly biased (but consistently underestimated). Misreporting has little effect on the performances of all $F_{0.1^{-}}$ based reference points. In summary, therefore, $F_{0.1}$ appears to be more accurate (i.e., less biased and more precise) than reference points based on biomass or yield $\left(B_{F_{01}}\right.$ and $\left.Y_{F_{01}}\right)$.

Even if estimates of $F$ and SSB (Fig. 1), reference points (Fig. 2), and $F_{0.1}$ relative to $F_{\mathrm{MSY}}$ (Fig. 3) are biased, reference points may still perform well in indicating whether the stock biomass is below $B_{\mathrm{MSY}}$ or whether $F$ is above $F_{\mathrm{MSY}}$. Therefore, we evaluated the performance of relative indicators defined by the ratio of $F, \mathrm{SSB}$, and yield to their corresponding $F_{0.1}$-based reference points (again by dividing these ratios to corresponding ratios from the OM), e.g., $\bar{F}: F_{0.1}$ (where $\bar{F}$ is the mean value of $F$ of the MP over the $F: F_{\text {MSY }}$ 
Fig. 4. A comparison of the ratios of $F$, spawning stock biomass (SSB), and maximum sustainable yield to their corresponding $F_{0.1^{-}}$ based reference points divided by the corresponding ratios from the operating model) e.g., $\frac{\bar{F}: F_{0.1}}{F: F_{\mathrm{MSY}}}(\bar{F}$ being the mean value of $F$ of the management procedure (MP) over the past 5 years). (a) All scenarios with constant historical $F$ s under the carrying-capacity hypothesis $\left(H_{K}\right) ;(b)$ all scenarios with constant historical $F$ s under the migration hypothesis $\left(H_{M}\right) ;(c)$ same as $(a)$ with misreporting; $(d)$ same as $(b)$ with misreporting; $(e)$ all scenarios with increasing historical $F$ s under the $H_{K}$; $(f)$ all scenarios with increasing historical $F$ s under the $H_{M}$.

Carrying-capacity hypothesis
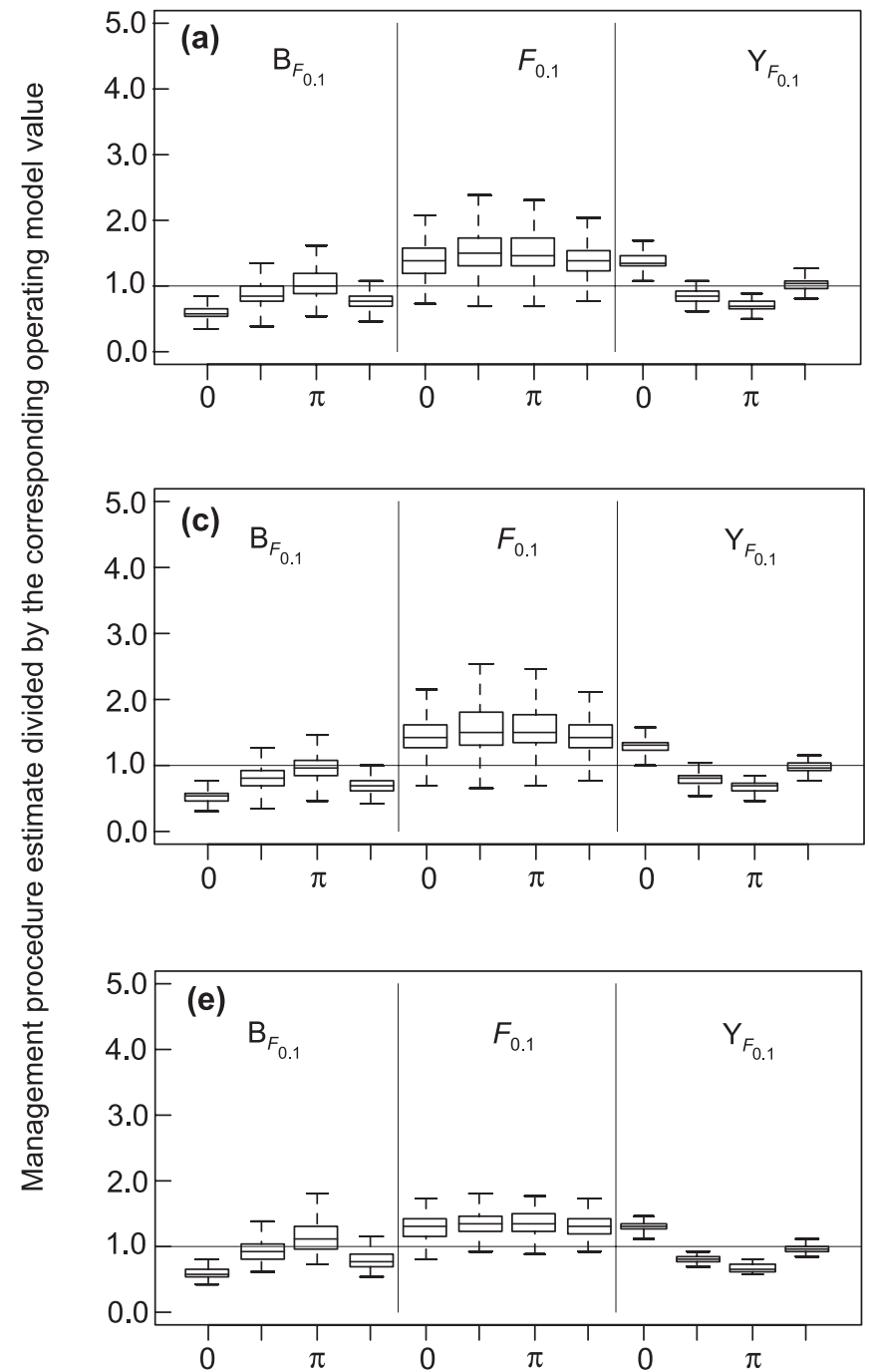

Phase
Migration hypothesis

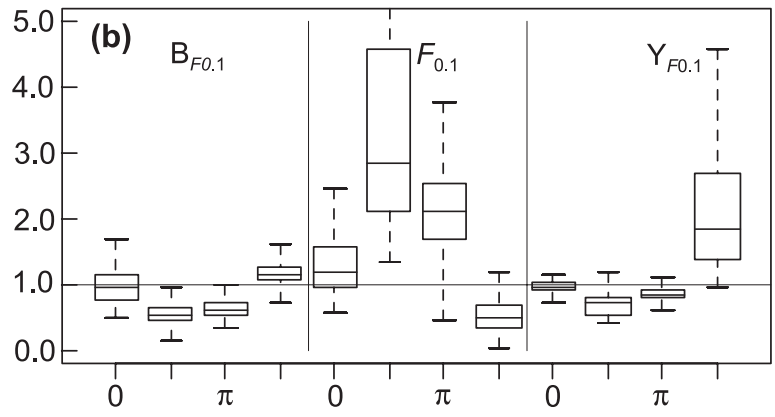

$\frac{\infty}{0}$
$\stackrel{\infty}{ \pm}$
$\stackrel{0}{0}$
$\stackrel{2}{2}$

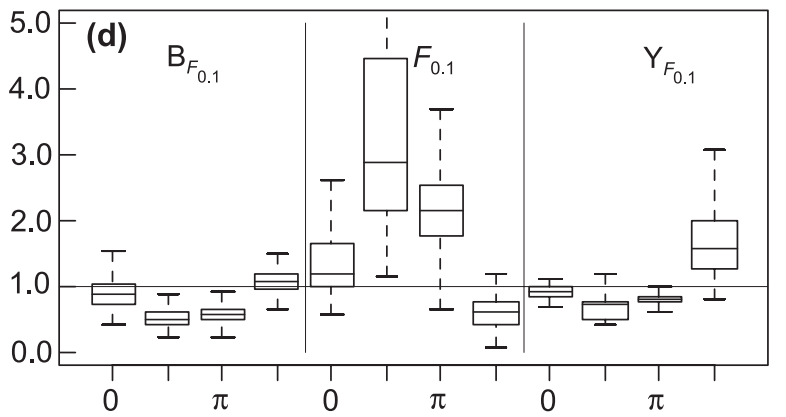

$\frac{D}{5}$
$\frac{.}{0}$
$\frac{0}{0}$
$\frac{0}{0}$
$\frac{0}{E}$
$\infty$
$\frac{0}{0}$
0
$\frac{0}{1}$
0
$\frac{2}{1}$

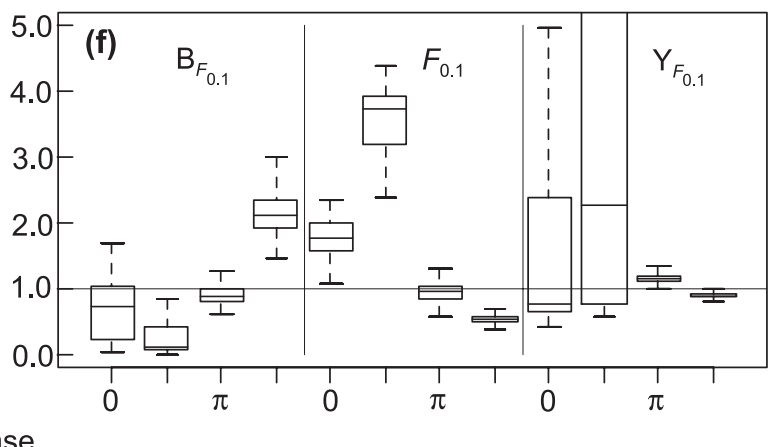

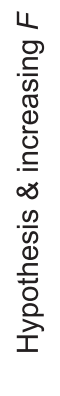

past 3 years, as performed by ICCAT, as recent VPA estimates are the most uncertain). In contrast to previous results (i.e., estimates of $F_{0.1}$ relative to $F_{\mathrm{MSY}}$ ), $F$-based quantities exhibit the greatest biases and, most often, the largest variations (Figs. 4b, 4d, 4f). Both hypothesis and starting point are important in determining the accuracy of these estimates, which are again more biased and much less precise under $H_{M}$ than under $H_{K}$, because VPA performs poorly under $H_{M}$ (see above). Here again, misreporting has little effect on the performance of $F$-based quantities, but increasing historical $F$ s have. In summary, the $F$-based quantities (i.e., $F$ relative to $F_{0.1}$ ) lead to unreliable estimates (especially under $H_{M}$ ) and are more biased and more variable than $F_{0.1}$-based refer- ence points. Consequently, it appears risky to indicate past and current levels of exploitation relative to $F_{\text {MSY }}$ when there is uncertainty about the actual dynamics.

\section{Evaluation of management procedures}

The evaluation of reference points is best performed as part of a management procedure that includes the harvest control rule and stock assessment method (Kell et al. 2006). Therefore, the performances of an $F_{0.1}$-based MP was evaluated and compared with the status quo (i.e., current effort levels) and an alternative in which selection pattern (rather than $F$ ) was the management variable in Fig. 5. The $F_{0.1^{-}}$ based MP is an attempt to implement ICCAT management 
Fig. 5. Comparison of a management procedure (MP) based on a harvest control rule (HCR) based on $F_{0.1}\left(F_{0.1} \mathrm{HCR}\right)$ with a $\mathrm{MP}$

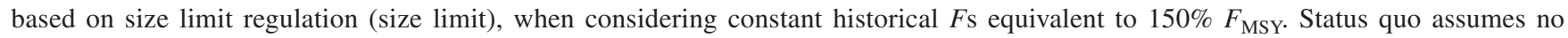
regulation. Yield or spawning stock biomass (SSB) of each MP is given relative to the maximum possible yield and to virgin biomass, respectively. The maximum yield is found by harvesting all fish when production attributable to growth becomes less than that lost to natural mortality; for Atlantic bluefin this is at age 13 (under $H_{M}$, MSY is 17500 , but the maximum yield is 42500 ). (a) Comparison of MPs in terms of yield under the carrying-capacity hypothesis $\left(H_{K}\right) ;(b)$ same as $(a)$ under the migration hypothesis $\left(H_{M}\right)$; $(c)$ comparison of MP in terms of SSB under the carrying-capacity hypothesis $\left(H_{K}\right) ;(d)$ same as $(c)$ under the migration hypothesis $\left(H_{M}\right)$.
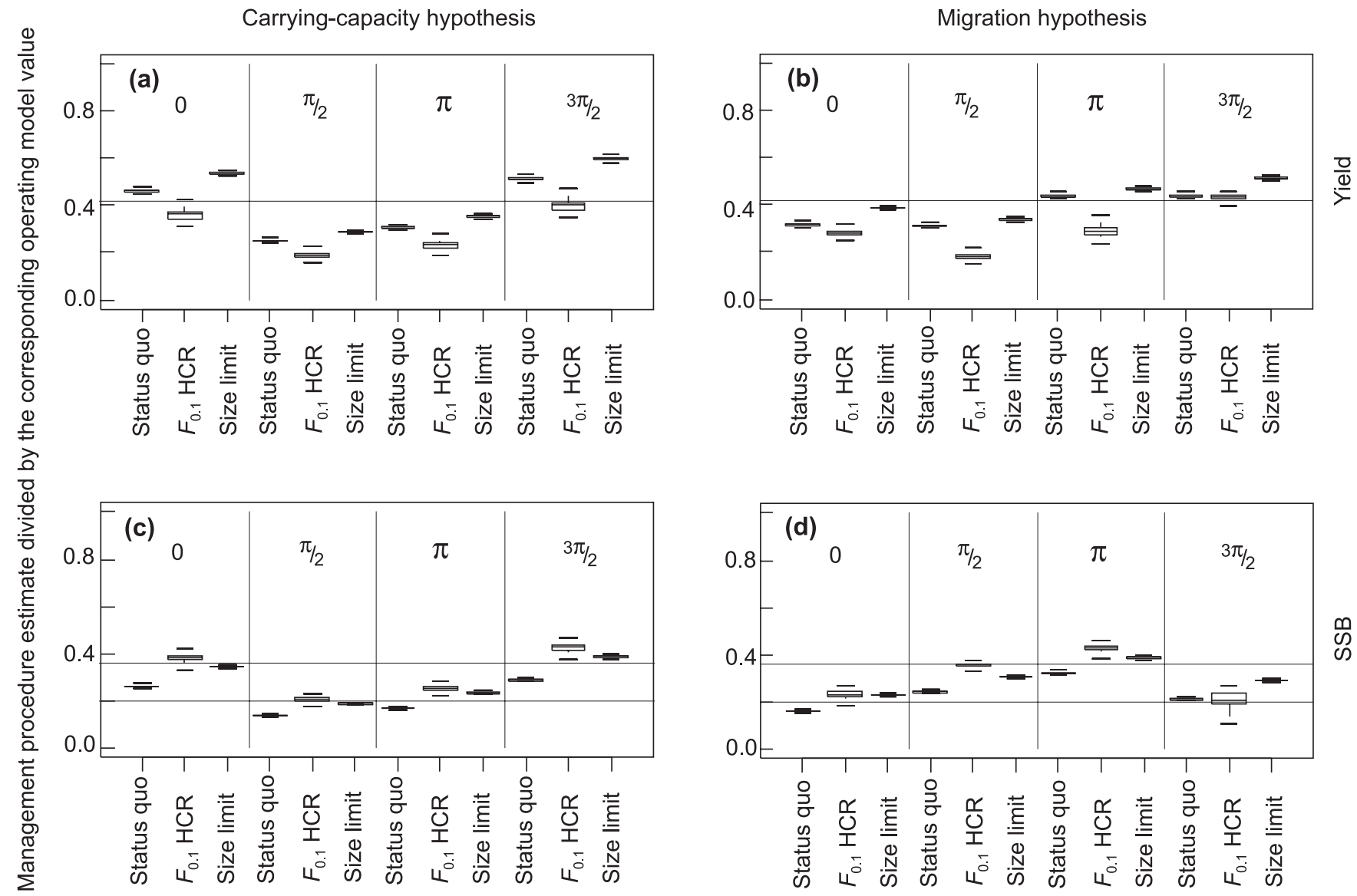

Results of Management Procedure

objectives in a harvest control rule intended to achieve MSY. In contrast, the alternative MP solely relies on size limit regulation and does not modify fishing effort (the size limit set at age-at-maturity, i.e., 5 years, with a $25 \%$ of tolerance for younger ages to take into account fisheries targeting juveniles).

Performances of both MPs were based on summary statistics from the OM after 15 years of implementation (one generation time) and were evaluated by comparison with the status quo (i.e., no regulation). The results are depicted by phases when considering constant historical $F$ s equivalent to $150 \% F_{\mathrm{MSY}}$, which is a scenario closer to the current fishing pressure than the others, i.e., $50 \%$ and $100 \% F_{\mathrm{MSY}}$ (Fromentin and Powers 2005). As MSY depends on the selectivity pattern of the fleets (e.g., Powers 2005), yield is expressed relative to maximum possible yield and SSB relatively to virgin biomass. In addition, MSY, $B_{\mathrm{MSY}}$ (calculated for the current selectivity pattern), and the biomass level corresponding to $75 \%$ of the "virgin recruitment" (i.e., biomass limit for recruitment-overfishing when the steepness of the stock-recruitment relationship equals 0.75 , denoted $B_{75 \% R}$ ) are shown as horizontal lines for comparison.

Relative yields under both management strategies vary between $20 \%$ and $60 \%$ of the maximum yield. Differences appear to be due mostly to management strategy and starting point and less to the underlying hypothesis $\left(H_{M}\right.$ or $\left.H_{K}\right)$. Although higher yields are seen under $H_{K}$, the range of yields remains indeed similar under both hypotheses. Regarding the MP, expected yields are always highest under the size limit strategy (up to $60 \%$ of maximum yield), second highest under status quo, and lowest under the $F_{0.1}$ strategy (where they do not exceed $40 \%$ of the maximum yield; Figs. $5 a$, $5 b)$. However, the performance of a given management strategy also depends on when it is implemented relative to the intrinsic cycle of the population. The expected SSBs are in general similar to or slightly higher under the $F_{0.1}$ than under the size limit strategy (Figs. $5 c, 5 d$ ). Depending on starting points, SSBs are at $40 \%$ (about $B_{\mathrm{MSY}}$ ) or $20 \%$ (about $\left.B_{75 \% R}\right)$ of virgin biomass. Under the size limit strategy, SSB is always greater than the status quo, and in all the cases but 
Fig. 6. Comparison of a management procedure (MP) based on a harvest control rule (HCR) based on $F_{0.1}\left(F_{0.1} \mathrm{HCR}\right)$ with a MP based on size limit regulation (size limit), when considering increasing historical $F$ s. Status quo assumes no regulation. Yield or spawning stock biomass (SSB) of each MP is given relative to the maximum possible yield and to virgin biomass, respectively. The maximum yield is found by harvesting all fish when production attributable to growth becomes less than that lost to natural mortality; for Atlantic bluefin this is at age 13 (under $H_{M}$, MSY is 17500 , but the maximum yield is 42 500). (a) Comparison of MPs in terms of yield under the carrying-capacity hypothesis $\left(H_{K}\right) ;(b)$ same as $(a)$ under the migration hypothesis $\left(H_{M}\right) ;(c)$ comparison of MP in terms of SSB under the carrying-capacity hypothesis $\left(H_{K}\right) ;(d)$ same as $(c)$ under the migration hypothesis $\left(H_{M}\right)$.

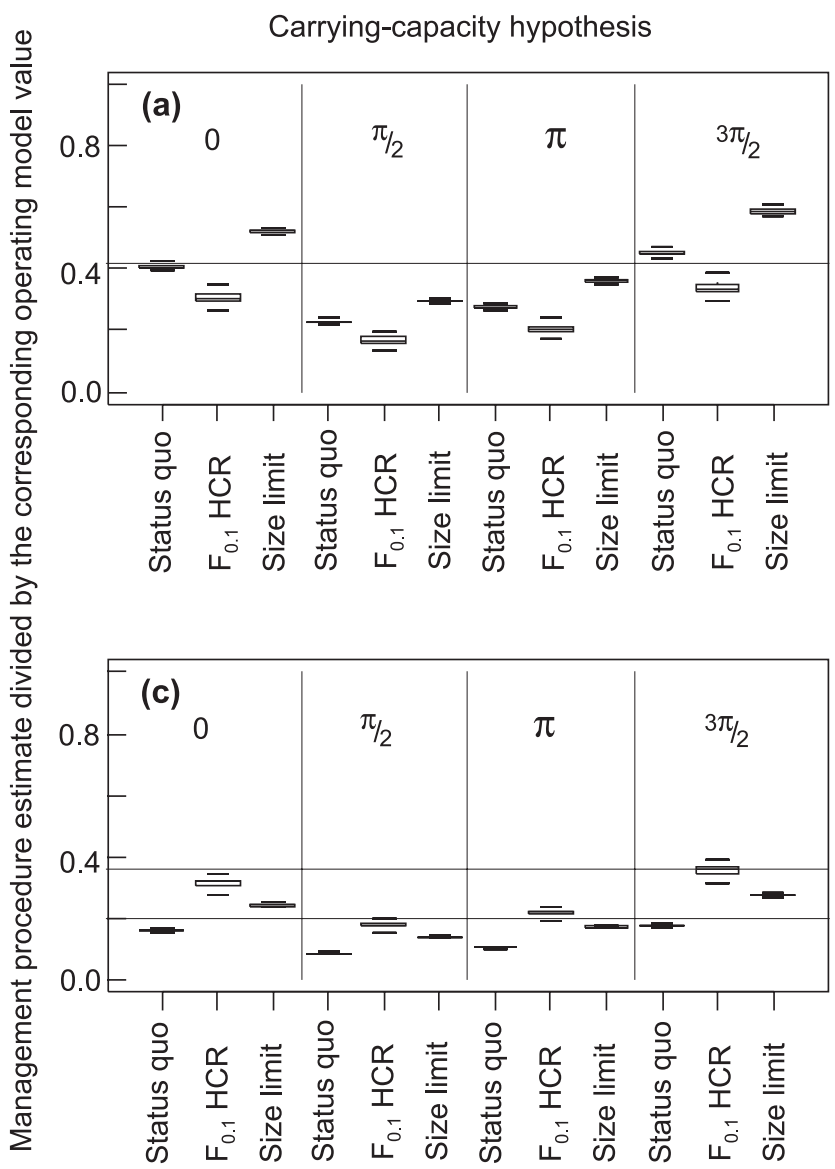

Migration hypothesis
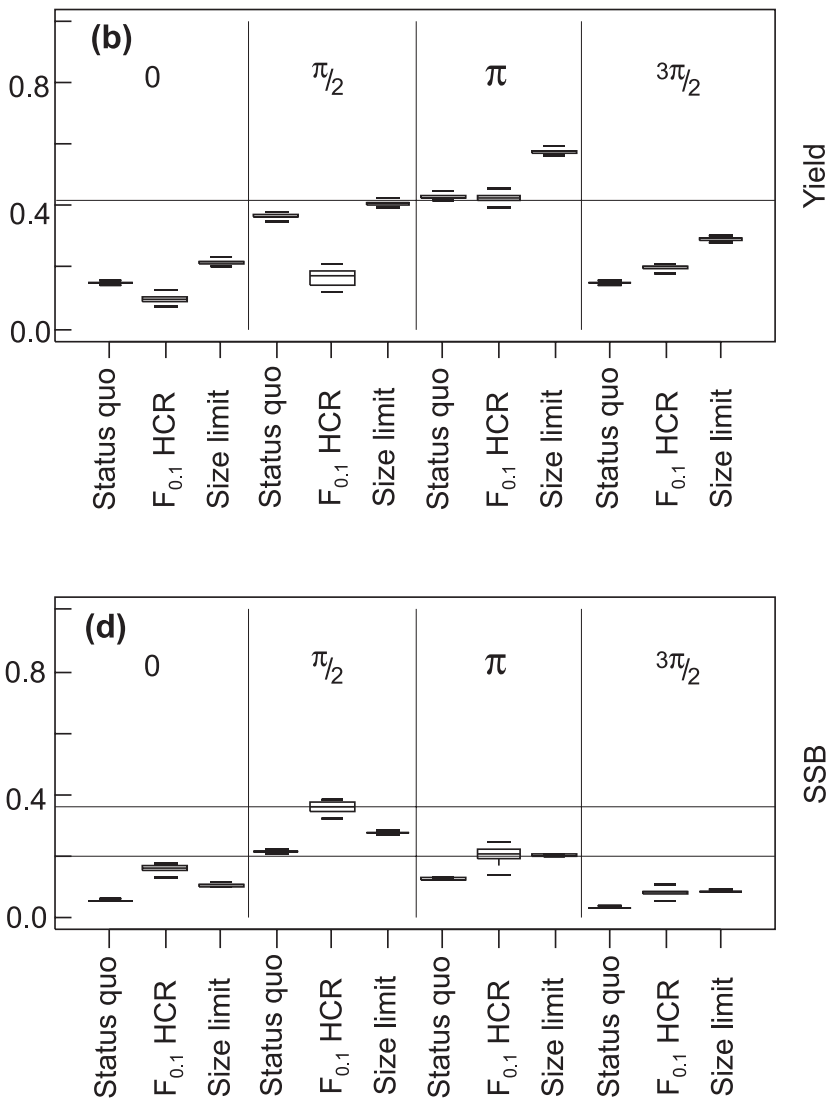

Results of Management Procedure

one, SSB remains greater than $20 \%$ virgin (a potential recovery level). The status quo generally leads to the lowest SSBs, which are sometimes under the $20 \%$ virgin limit.

Evaluation of the effect of increasing historical $F$ s instead of constant Fs is performed (Fig. 6), and it can be seen that yield patterns are comparable under $H_{K}$, but not under $H_{M}$, for which yields are clearly lower (and often below 20\% maximum yield; Figs. $6 a, 6 b)$. Again yields were higher under the size limit than under the $F_{0.1}$ strategy, but SSBs were generally lower (below $20 \%$ virgin in many cases; Figs. $6 c, 6 d$ ). Here again the performance of a given MP (for both yield and $\mathrm{SSB}$ ) depends on when it is implemented relative to the intrinsic cycle of the population. Although performance was poor for both hypotheses, both MPs performed better than the control. Notwithstanding, problems were more acute under $H_{M}$ because of the opposition of phase between $F$ and SSB (Fromentin and Kell 2007), which means that increasing effort can reinforce depletion for some starting points.

A size limit strategy generates greater yields than the more sophisticated $F_{0.1}$ but lower SSBs in some cases.
Further, more important than the underlying process $\left(H_{M}\right.$ or $H_{K}$ ) was the current phase of the cycle, because this strongly affected the performances of both management strategies.

\section{Discussion}

Fromentin and Kell (2007) showed that the ability to estimate stock size and fishing mortality accurately depends on the underlying processes that may cause long-term variation in the catches. The same conclusion is reached in this study, in which stochasticity in recruitment and sampling procedure, as well as implementation error (i.e., misreporting), were also incorporated. Where fluctuations are caused by changes in carrying capacity, the stock assessment procedure is able to estimate stock size and fishing mortality rate accurately, but fails in most cases if the fluctuations result from changes in migration pattern (i.e., availability to fishing). In other words, uncertainty about the true dynamics was more critical to the process than the assumed uncertainty attribut- 
able to misreporting and stochasticity in some biological processes.

The study demonstrated the following for both hypotheses $\left(H_{M}\right.$ and $H_{K}$ ): (i) $F_{0.1}$ was the best proxy for $F_{\mathrm{MSY}}$ (performing better than $F_{\max }$ and $F_{30 \% \mathrm{SPR}}$ ); (ii) reference points based on $F$ (e.g., $F_{0.1}$ ) were less biased and more precise than those based on yield and (or) SSB, e.g., $Y_{F_{01}}$ or $B_{F_{01}}$; and (iii) $F$-based reference points were more robust to uncertainty about the true dynamics than absolute estimates in fishing mortality and SSB, but (iv) their ability to predict exploitation level relative to $F_{\text {MSY }}$ was poor (and less than those based on yield and (or) SSB). Therefore, reference points such as $F_{0.1}$ appear to be more robust to dynamic uncertainty than absolute estimates of $F$ and SSB and perform, as a whole, satisfactorily. Unfortunately, however, $F_{0.1}$ cannot indicate past and current levels of exploitation relative to $F_{\text {MSY }}$ when there is uncertainty about the dynamics. Therefore, although reference points such as $F_{0.1}$ may be good proxies for $F_{\mathrm{MSY}}$, the MSY concept may be difficult to make operational when trends in yield can occur, either through variations in carrying capacity $\left(H_{K}\right)$, migration $\left(H_{M}\right)$, or effort.

Traditionally, MSY-based strategies are conditional upon a mean selection pattern in the fishery, which in practice assumes fixed effort allocation between fleets. However, the maximum catch is actually found when all individuals above a certain age are harvested (Beddington and May 1977), i.e., when losses attributable to natural mortality become greater than the gains through growth. As Powers (2005) pointed out, the determination of reference points (such as MSY) depends on the selectivity of the various fleets, the relative mix of fleets that management desires, and any bycatch in nontarget fisheries. This could be achieved either by changing the relative fleet composition (i.e., reducing the effort of fleets targeting juvenile fish) or by forcing existing fleets to be more selective (e.g., imposing a size limit on the catch). The actual choice depends as much on socio-economic and operational factors as on biological considerations. Therefore, economic and biological objectives need to be stated explicitly, so that trade-offs between risk to a stock, yield levels, and employment opportunities can be fully evaluated across fleets and national sectors.

An alternative to an $F_{0.1}$ strategy could be simply setting a size limit with or without constraints on effort. This would also require less knowledge about stock dynamics and might provide an alternative that is more robust to uncertainty about biological processes. An additional benefit would be that the logic of allowing more fish to spawn at least once would be more transparent than a management strategy based on VPA, $F_{\mathrm{MSY}}$ (or $F_{0.1}$ ), and catch quotas.

An evaluation of alternative management strategies was performed through simulation in order to take the various sources of uncertainty into account, including lack of knowledge about dynamic processes, consistent with the principles of the precautionary approach (FAO 1996). When the $F_{0.1^{-}}$ based MP and an alternative based on a size limit were evaluated with respect to uncertainty about the true dynamics, the performances of both management strategies were quite similar but strongly dependent on the phases, i.e., the period over which they are implemented relative to the in- trinsic cycle of the population. However, as stock size does not fluctuate synchronously with the catch under $H_{M}$ and as we cannot determine the real underlying process without fishery-independent data or scientific study (see Fromentin and Kell 2007), it will be difficult to determine what the true dynamics are or even what phase the cycle is in. It will therefore be difficult to distinguish between natural and anthropogenic changes, to detect changes in productivity, and to revise reference points without fishery-independent data and targeted scientific studies on the biology and ecology of the population. Note also that Fromentin and Kell (2007) showed that there may be no simple stock-recruitment relationship if SSB is lagged with recruitment.

An $F_{0.1}$ MP based on ADAPT-VPA stock size estimates only performed slightly better than a strategy based on a simple size limit. Further, the former led to much lower catch levels than the latter. Note, however, that yield and SSB are not strictly comparable, because reference points under the two management scenarios would be different. Although under the $F_{0.1}$ strategy $B_{\mathrm{MSY}}$ is not an appropriate target, a biomass limit may be more appropriate for the size limit strategy, because it would be more important to ensure that recruitment is not impaired rather than that the stock is at $B_{\mathrm{MSY}}$. For example, an appropriate biomass limit in the case of a stock-recruitment relationship with a steepness value of 0.75 might be $20 \%$ of virgin biomass, because at this level, recruitment need only be $75 \%$ of the unexploited level. However, such a limit would have to be decided upon taking uncertainty and management objectives into account.

Finally, the performances and robustness of distinct management strategies depend on (i) biological processes (i.e., the underlying dynamics), (ii) phases (when they are implemented relative to the stock size cycle), and also (iii) concrete objectives, such as fleet composition, gear selectivity, and economic constraints. For example, the two management strategies have different implications for choice of reference points; the $F_{0.1}$ strategy is based on a target fishing mortality and hence effort, whereas the size limit strategy has an implicit biomass limit (i.e., the minimum biomass of immature fish). The two strategies also imply different management objectives. For example, a size limit strategy will reduce effort or yield for certain fleets more than others, whereas an $F_{0.1}$ strategy implies an equal cut in effort by all fleets. The choice of a strategy cannot therefore be decided on a purely scientific basis, but rather through its performances relative to the main management objectives, fisheries constraints, and biological and ecological processes postulated (Powers and Porch 2004; Kell et al. 2005). Such investigations are best conducted through the type of simulations of management strategies performed in this study.

Options are to develop management strategies that are robust to uncertainty about the dynamics (e.g., a size-selectivity management strategy), to reduce uncertainty by improving biological knowledge (e.g., use of new techniques to monitor spawning ground or migration routes such as listening stations along the Gibraltar Strait or the large-scale tagging of juvenile fish with electronic chips), or to develop more elaborate population dynamics models such as a VPA that includes spatial stratification and the statistical estimate of migration coefficient between the Atlantic and Mediterranean Sea. However, difficulties in 
implementation of management regulations and therefore uncertainty about actual catches may make it difficult to use such an assessment method. Development of such methods should be simulation tested to evaluate their robustness to model assumptions and uncertainty about the data.

An incentive to resolve uncertainty could be provided by a strict implementation of the precautionary approach, i.e., by ensuring that there is a positive relationship between information and utilisation (Cooke 1999), so that the less known, the lower the level of exploitation. This means that there would be an incentive to resolve key uncertainties about the population dynamics by conducting appropriate scientific investigations or to develop robust alternatives. Only in this way can strategies be developed that are robust to uncertainty about our knowledge of stock dynamics and the ability to control fisheries, including noncompliance with regulations.

\section{Acknowledgements}

This paper was prepared with funding support provided by the UK Department for Environment, Food and Rural Affairs (DEFRA, under contract M0322) for LTK and by the European Commission Research Directorates through the EU FP5 project FEMS: Framework for Evaluation of Management Strategies (contract Q5RS-2002-01824). The authors thank Dr. A.I.L. Payne for comments and suggestions on earlier and final drafts.

\section{References}

Arrizabalaga, H. 2005. The effect of eastern Atlantic and Mediterranean bluefin tuna sampling error on the catch-at-age. Coll. Vol. Sci. Pap. ICCAT, 58: 791-797.

Beddington, J.R., and May, R.M. 1977. Harvesting natural populations in a randomly fluctuating environment. Science (Washington, D.C.), 197: 463-465.

Beverton, R.J.H., and Holt, S.J. 1957. On the dynamics of exploited fish populations. Fish. Investig. Lond. Ser. 2, No. 19.

Birkeland, C., and Dayton, P.K. 2005. The importance in fishery management of leaving the big ones. Trends Ecol. Evol. 20: 356-358.

Cooke, J.G. 1999. Improvement of fishery-management advice through simulation testing of harvest algorithms. In Confronting uncertainty in the evaluation and implementation of fisheriesmanagement systems. Edited by A.I.L. Payne. ICES J. Mar. Sci. 56: $797-810$.

Dorn, M. 2002. Advice on west coast rockfish harvest rates from Bayesian meta-analysis of stock-recruit relationships. N. Am. J. Fish. Mgmt. 22: 280-300.

Doulman, D.J. 1995. Structure and process of the 1993-1995 United Nations conference on straddling fish stocks and highly migratory fish stocks. FAO Fish. Circ. No. 898.

Food and Agricultural Organization of the United Nations. 1996. Precautionary approach to capture fisheries and species introductions. Technical Guidelines for Responsible Fisheries No. 2. Food and Agricultural Organization of the United Nations, Rome, Italy.
Fromentin, J.-M., and Kell, L.T. 2007. Consequences of variations in carrying capacity and migration pattern for the perception of Atlantic bluefin tuna (Thunnus thynnus) population dynamics. Can. J. Fish. Aquat. Sci. 64: 827-836.

Fromentin, J.-M., and Powers, J.E. 2005. Atlantic bluefin tuna: population dynamics, ecology, fisheries and management. Fish Fish. 6: 281-306.

International Commission for the Conservation of Atlantic Tuna. 2003a. Basic texts. 3rd ed. ICCAT Publ., Madrid, Spain.

International Commission for the Conservation of Atlantic Tuna. 2003b. Report of the 2002 Atlantic bluefin tuna stock assessment session. Coll. Vol. Sci. Pap. ICCAT, 55: 710-937.

International Commission for the Conservation of Atlantic Tuna. 2005. Report of the 2004 data exploratory meeting for the East Atlantic and Mediterranean bluefin tuna. Coll. Vol. Sci. Pap. ICCAT, 58: 662-699.

International Commission for the Conservation of Atlantic Tuna. 2007. Report of the 2006 Atlantic bluefin tuna stock assessment session. Coll. Vol. Sci. Pap. ICCAT, 60. In press.

Jennings, S., Greenstreet, S.P.R., Hill, L., Piet, G.J., Pinnegar, J.K., and Warr, K.J. 2002. Long-term trends in the trophic structure of the North Sea fish community: evidence from stable isotope analysis, size-spectra and community metrics. Mar. Biol. 141: 1085-1097.

Kell, L.T., Pilling, G.M., Kirkwood, G.P., Pastoors, M., Mesnil, B., Korsbrekke, K., Abaunza, P., Aps, R., Biseau, A., Kunzlik, P., Needle, C., Roel, B.A., and Ulrich-Rescan, C. 2005. An evaluation of the implicit management procedure used for some ICES roundfish stocks. ICES J. Mar. Sci. 62: 750-759.

Kell, L.T., De Oliveira, J.A.A., Punt, A.E., McAllister, M.K., and Kuikka, S. 2006. Operational management procedures: an introduction to the use of management strategy evaluation frameworks. In The knowledge base for fisheries management. Edited by L. Motos and D.C. Wilson. Developments in Aquaculture and Fisheries Science No. 36. Elsevier, Amsterdam. pp. 379407.

Kirkwood, G.P., and Smith, A.D.M. 1996. Assessing the precautionary nature of fishery management strategies. In Precautionary approach to fisheries. Part 2. Scientific Papers. FAO Fish. Tech. Pap. 350: 141-158.

Porch, C.E. 1997. A user's manual for VPA-2BOX version 2.0. National Marine Fisheries Service, Miami, Fla.

Powers, J.E. 2005. Maximum sustainable yield and bycatch minimization "to the extent practicable". N. Am. J. Fish. Mgmt. 25: $785-790$

Powers, J.E., and Porch, C.E. 2004. Approaches to developing management procedures which incorporate mixing. Coll. Vol. Sci. Pap. ICCAT, 56: 1144-1152.

Punt, A.E. 2000. Extinction of marine renewable resources: a demographic analysis. Popul. Ecol. 42: 19-27.

Punt, A.E., and Smith, A.D.M. 1999. Harvest strategy evaluation for the eastern stock of gemfish (Rexea solandri). In Confronting uncertainty in the evaluation and implementation of fisheries-management systems. Edited by A.I.L. Payne. ICES J. Mar. Sci. 56: 860-875.

Rosenberg, A.A., and Restrepo, V.R. 1994 Uncertainty and risk evaluation in stock assessment advice for U.S. marine fisheries. Can. J. Fish. Aquat. Sci. 51: 2715-2720.

Sainsbury, K.J., Punt, A.E., and Smith, A.D.M. 2000. Design of operational management strategies for achieving fishery ecosystem objectives. ICES J. Mar. Sci. 57: 731-741. 